\title{
Estimation of The Structural Pattern and Sedimentary Thickness Over Part of Anambra Basin, Nigeria Using Aeromagnetic Data
}

\author{
Priscilla E. Ikiodaa, Charles O. Ofoegbu ${ }^{b}$, Etim D. Ukoc, ${ }^{\text {, }}$ and Olatunji S. Ayanninuola \\ a Department of Physics, Nasarawa State University, PMB 1022, Keffi, Nigeria. \\ b Institute of Geosciences and Earth Resources, Nasarawa State University, PMB 1022, Keffi, Nigeria. \\ ${ }^{c}$ Department of Physics, Rivers State University, PMB 5080, Port Harcourt, Nigeria. \\ *Corresponding author E-mail: e uko@yahoo.com
}

\section{DOI: $10.2478 / p j g-2021-0002$}

\section{Abstract:}

Aeromagnetic data acquired over part of the Anambra Basin is analyzed to determine the structural pattern and sedimentary thickness of the basin. The study area is covered by high resolution aeromagnetic data on sheets 301 (Udi), 302 (Nkalagu), 312 (Okigwe) and 313 (Afikpo), and lies between latitudes $5^{\circ} 30^{\prime} 0^{\prime \prime}-6^{\circ} 30^{\prime} 0^{\prime \prime}$ and longitudes $7^{\circ} 0^{\prime} 0^{\prime \prime}-8^{\circ} 0^{\prime} 0^{\prime \prime}$. The whole area was divided into 25 overlapping blocks of $37.2 \mathrm{~km}^{2}$ each and a $2 \mathrm{D}$ energy spectral analysis was carried out. Total magnetic intensity data was subjected to filtering and analytical techniques to determine the structural pattern, mineralization potential, depth to the basement, variation in the sedimentary thickness. The structural map generated using the vertical derivatives shows that the major structural orientation of the area is in the ENE-WSW trend and the minor trend is the NW to SE direction widespread all over the area. These structures are as a result of the various near-surface magnetic intrusion within the study area. The spectral analysis result shows two depth layers, the deep and the shallow depth, the depth to magnetic basement for the deep anomalous source ranges from $3.3 \mathrm{~km}$ to $4.84 \mathrm{~km}$ with an average depth of $3.99 \mathrm{~km}$, while the depth to shallow magnetic sources ranges between $0.46 \mathrm{~km}$ to $0.67 \mathrm{~km}$ and an average of $0.56 \mathrm{~km}$ within the area. The mineralization pattern in this area follows the ENE-WSW direction.

Keywords: aeromagnetic, structures, sedimentary, minerals, Anambra Basin, Nigeria

\subsection{Introduction}

The magnetite content of rocks varies considerably and as a result, the susceptibility of rocks is also extremely variable and there can be signific ant overlap in susceptibility between different rocks [1,2]. Magnetic anomalies may result from dykes, faulted, folded or truncated sills and lava flows, massive basic intrusions, metamorphic basement rocks and magnetite ore bodies [3, 4]. The study area and its environs have been surveyed and studied by several geoscientists [5 - 12]. The results of their study confirm the existence near-surface basement rocks, massive igneous body at shallow depth, existence of NE-SW, NW-SE and E-W lineaments trending features, at depth varying between 0.4 and $4.99 \mathrm{~km}$. This present study uses the aeromagnetic data to delineate and outline the local subsurface geological structures, sedimentary thickness, depth to basement, and faults over part of Anambra Basin Nigeria.

\subsection{The Study Area and Regional Geology}

Anambra Basin is located within Latitudes $7^{\circ} 0^{\prime} 0^{\prime \prime}$ and $8^{\circ} 0^{\prime} 0^{\prime \prime} \mathrm{E}$ Longitudes $5^{\circ} 30^{\prime} 0^{\prime \prime}$ and $6^{\circ} 30^{\prime} 0^{\prime} \mathrm{N}$ (Figure 1), and is bounded on the east by the Abakaliki Anticlinorium and on the south west by the Benin hinge-line, while the southern extreme is marked by the upper limits of the Eocene growth faults of the Niger Delta [13]. The basin is about 3,000 $\mathrm{km}^{2}$ and having sedimentary thickness of about $9 \mathrm{~km}$, and the dominant lithologies comprise sandstones, shales, limestone and coal seams [14 -17].

\subsection{Materials and Methods}

\subsection{Data Acquisition and Data Quality Control}

The map of the study area was broken into 25 overlapping spectral blocks of $37.22 \mathrm{~km}$ labelled 1 to 25 each; the Grid mesh size was 125 meters (Figure 2). The aeromagnetic data acquired by Furgro Airborne Surveyors between the years 2005 and 2009 on behalf of Nigerian Geological Survey Agency (NGSA). The survey was carried out at 0.05 seconds magnetic data recording interval, at $80 \mathrm{~m}$ terrain clearance; while the flight line spacing was at 135 degrees flight line trend. Tie line spacing was at 225 degrees tie line trend. Caesium Vapour Magnetometer was used for the survey.

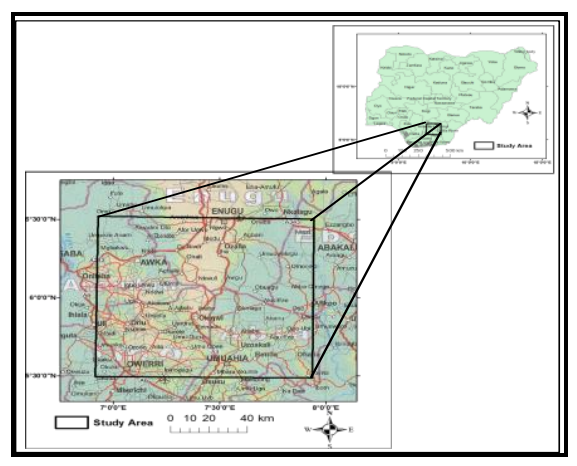

Figure 1. Location Map of the Study Area [18]

\subsection{Data Quality Control, Processing and Enhancements}

Preliminary processing and interpretations were carried out by Paterson, Grant \& Watson Limited (PGW) which performed the geomagnetic gradient removal from raw data using the International Geomagnetic Reference Field (IGRF). Other preliminary processing routines include removal of the Earths background magnetic field, aircraft, Radon and cosmic background noises, stripping, micro-levelling, diurnal variation of the earths' magnetic field, 
aircraft heading, instrument variation, lag error between the aircraft and the sensor and inconsistencies between flight lines and tie lines. cultural noise and diurnal variations. Since the data was acquired at low latitude where anomalies are subtle and more complex, enhancement techniques were employed for accurate positioning of geological boundaries and magnetic sources [12]. The main software used for processing and enhancement of the data was the Geosoft (Oasis Montaj), ArcGIS was used to create the GIS environment for the integration of the interpreted results. The 3D map was produced using the Surfer-11 and the rose diagram was produced using the Rockwork software- 16 .

\subsection{Data Reduction to Magnetic Equator (RTE)}

The total magnetic intensity (TMI) data were reduced to equator. Magnetic anomaly interpretation is mostly based on the theory of vertical magnetization. The interpretation becomes more complex at low latitudes due to the influence of dip magnetization, especially at the equator [12]. Reduction to pole (RTP) is an important processing for aeromagnetic surveys, and it is the basis of magnetic anomaly interpretation. RTP takes convolution in space domain to reduce the effect of dip magnetization. RTP at low latitudes, routinely computed in Fourier domain, is notoriously unstable. The reduction to equator technique calculates the TMI data as if the inducing magnetic field had a 0 o inclination. For the purpose of this study, the reduction to equator technique was applied because the study area is close to the equator. The map resulting from this process is shown in Figure 3.

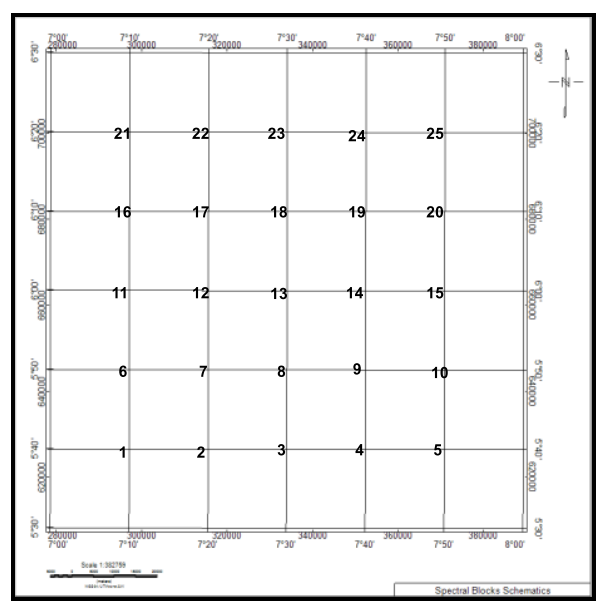

Figure 2. Schematics division of the 25 spectral blocks from 1 to 25 of $37.2 \mathrm{~km}^{2}$ each.

\subsection{Upward Continuation}

Upward continuation is a smooth filter attenuating amplitude progressively with increasing wavenumber. The upward continuation is also characterized as a powerful lowpass filter, because the low or weak frequencies are priority, those high are simply cut. The residual is defined as the subtraction of the upward continued total field anomaly from the total field anomaly. The upward continuation expresses regional structural directions. The technique of residual-regional separation based on an upward continuation of the anomaly is connected to the immediate effect of the distance between the sources and the plan of measurement. Since the distance increases upward, the signals of the surface sources are attenuated [5]. The upward continuation is a residual and regional anomaly separation method [5]. Since the distance increases upward, the signals of the surface sources are attenuated [5]. In the space domain, the upward continuation is described by the integral as follow:

$U\left(x, y, z_{o}-\Delta z_{o}\right)=\frac{\Delta z}{2 \pi} \iint_{-\infty}^{+\infty} \frac{U\left(x^{\prime}, y^{\prime}, z_{o}\right)}{\left[\left(x-x^{\prime}\right)^{2}+\left(y-y^{\prime}\right)^{2}+\Delta z^{2}\right]^{3 / 2}} d x^{\prime} d y^{\prime}, \Delta z>0$

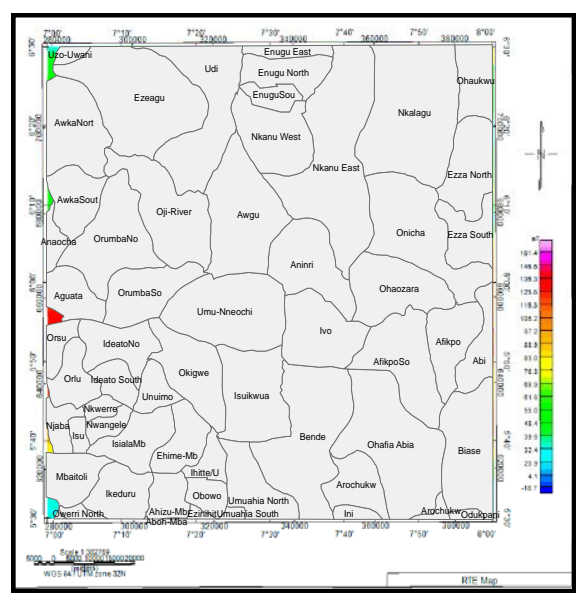

Figure 3. The Total Magnetic Intensity Map reduced to the Equator.

where $\mathrm{U}$ is the gravity or magnetic potential field; $\mathrm{z}_{0}$ is the initial observation plan; $\Delta \mathrm{z}$ is the continuation distance. Vertical distance $\mathrm{Z}$ is positive downwards. Upward continuation consists in attenuating the amplitude and smoothing thus transforming the anomaly from the altitude $\mathrm{z}=0$ to the altitude $\mathrm{z}>0$ [12]. 


\subsection{The Analytic Signal}

Analytical signal method is a popular gradient enhancement, which is related to magnetic fields by the derivatives. [9] showed that the amplitude of the analytic signal can be derived from the three orthogonal gradient of the total magnetic field using the expression:

$$
|A(x, y)|=\sqrt{\left[\left(\frac{d T}{d x}\right)^{2}+\left(\frac{d T}{d y}\right)^{2}+\left(\frac{d T}{d z}\right)^{2}\right]}
$$

where $A(x, y)$ is the amplitude of the analytical signal at $(x, y)$ and $T$ is the observed Total Magnetic Field at $(x, y, z)$. While this function is not a measurable parameter, it is extremely interesting in the context of interpretation, as it is completely independent of the direction of magnetisation and the direction of the Earth's field [9]. Analytic signal method is used mapping and imaging source position regardless of any remnant magnetization in the sources [9]. The analytic signal data enhancement technique was employed in this study to define properly the edges of magnetic anomalies.

\subsection{The Vertical Derivatives Filters}

The importance of vertical derivatives is to locate the position of the density or magnetization boundaries. The RTE-TMI image contains both the shallow and deep sources anomalies. Therefore, second vertical derivatives (SVD) filtering was used to suppress unwanted sources that were obscured by broader regional trend by sharpening the edges of the anomalies. Furthermore, derivative filters reduce anomaly complexity and allow sharper contrast between the geologic unit sand causative structures like lineaments/faults and smaller trends [12].

\subsection{Regional and Residual Fields}

The total magnetic field intensity is made up of the regional and the residual fields. The regional field most often masks the residual fields. In the interpretation, the higher frequency regional fields were separated from the low frequency residual fields. The separation was achieved by polynomial fitting using multiple regression analysis. The subtraction of the calculated regional values from that of the original magnetic field intensity values gives the residual values.

\subsection{Results and Discussion}

\subsection{Total Magnetic Intensity Reduced to the Equator Map}

The Total magnetic intensity map of the study area was reduced to the equator (RTE), the RTE Map shows the variation in magnetic intensity from the RTE map, and for the RTE map the magnetic intensity is directly proportional to the magnetic susceptibility, i.e. high intensity is high susceptibility. The magnetic intensity values for the RTE map ranges from 18.7 to $161.4 \mathrm{nT}$. There is also observed variation in the wavelength of the signature, those with short wavelength are from the shallow basement while those with long wavelength are those signals from considerable depth within the area.

\subsection{The Residual Magnetic Intensity Map of the Study Area}

There is variation in magnetic intensity values ranging from -81.272 to $59.507 \mathrm{nT}$. These are as a result of the occurrence of a high susceptible rock within those areas. There also occurs a sharp gradation in the magnetic signature from very low to very high in the area around Umu-Neochi towards its southern part to Isuikwua area. However, most of the positive susceptibility values from the study area are as a result of the nearness of the basement to the surface within the area as most part of the area is largely sedimentary terrain with few outcrop occurrences. Areas with low magnetic intensity and long wavelength are areas around Ezeagu, and Udi, the northern part of Umu-Nneochi, and the South-eastern part of the study area which is the areas around Arochukwu. These areas have thick sedimentary cover and low magnetic susceptible basement type.

\subsection{The Regional Map}

The regional anomaly map of the study area enhances those anomaly resulted from the deep basement and eliminates the remanent magnetization effect or the localized anomalous effect. The regional anomaly map of the study area shows an E-W and a NE-SW trend for various part of the study area as seen in Figure 4.

\subsection{Analytical Signal Map}

The map of the analytical signal (Figure 3) shows similarity in trend with the residual anomaly. Areas in the south-western part of Nkalagu have low or no response to the analytic signal. This is as a result of the area being occupied by sedimentary rock of considerable thickn ess, other areas on the map are littered with various positive amplitude analytical signal which is an indicative of basement or near surface intrusion.

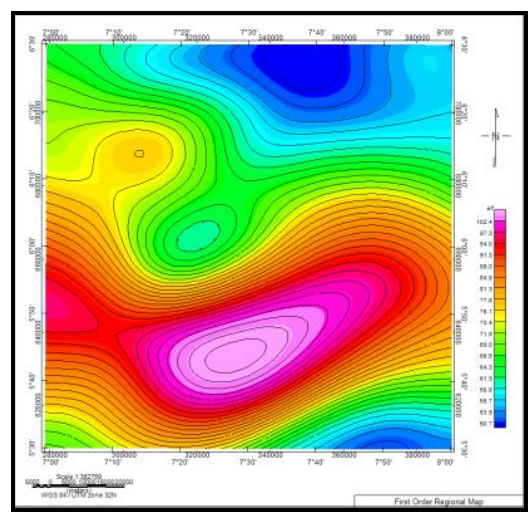

Figure 4. The Regional anomaly map of the study area. 


\subsection{Vertical Derivative Map}

The second vertical derivative was used to delineate and estimate the depths to the basement formed the basis of aeromagnetic interpretation. The first and the second vertical derivatives maps (Figures 5 \& 6) of the area shows the strongest magnetic trends and different stages of deformation which has lead to the variation in the structural orientation which is a function of various deformational phases. The structural map was extracted from the first vertical derivatives map; the major trend is in the ESE-WSW, while the minor is in the NW-SE trend (Figures 7).

\subsection{Spectral Analysis}

The power spectrum, obtained through Fourier transform, of the surface field was be used to identify average depths of source ensembles. The result was grouped into two intervals (or two main sources depth). The shallow magnetic horizons represented by the second segments are thought to reflect sources shallower than the Precambrian. The depth to Precambrian basement for the deep sources have a depth ranges from 3253.752 to $4837.183 \mathrm{~m}$ and an average depth of $3987.8 \mathrm{~m}$, while the shallow depth sources ranges from a depth of 458.56 to a depth of about $673.845 \mathrm{~m}$ and an average of $558.1441 \mathrm{~m}$.

\subsection{Structural Map of The Study Area}

Areas with deep basement are areas with thick sediments cover while areas with shallow basement sources are areas with thin s ediments cover. Also of note is those areas with a very positive analytical signal especially areas around Agwu and Isuikwua have thin sedimentary cover and shallow basement sources compared to other part of the map. These is as a result of the nearness of the basement to the surface as seen on the residual, analytic signal and the first vertical derivative map of the study area. There are variation in the various rock response to magnetism. Basement rocks usually have a positive magnetic signature while sedimentary rocks have no response magnetism. Rocks of the study area showed different aeromagnetic responses that can be related to their lithology and tectonic activities that have resulted in the geological structures (such as folds, faults and fractures) in the area.

\subsection{Conclusion}

Aeromagnetic data over Udi, Nkalagu, Okigwe and Afikpo was processed to analyse the structures which are potential host for mineralization and to estimate the depth to the magnetic basement and the sedimentary thickness within the area in order to be able to understand the mineralization potential of the area. The interpretation of the high-resolution airborne magnetic dataset has provided a synopsis of the regional geology as well as further insight into structural controls of the area. The general trend in the ENE-WSW and the NW-SE direction. The depth to the magnetic basement from ranges from $3.3 \mathrm{~km}$ to $4.8 \mathrm{~km}$ for deeper magnetic sources, and the shallow basement sources ranges from $0.56 \mathrm{~km}$ to $0.67 \mathrm{~km}$. Sedimentary thickness is highly variable within the study area with the deepest part falling in the South-western part of the map, and the shallow basement occurring around Agwu and Isuikwua area of the map.

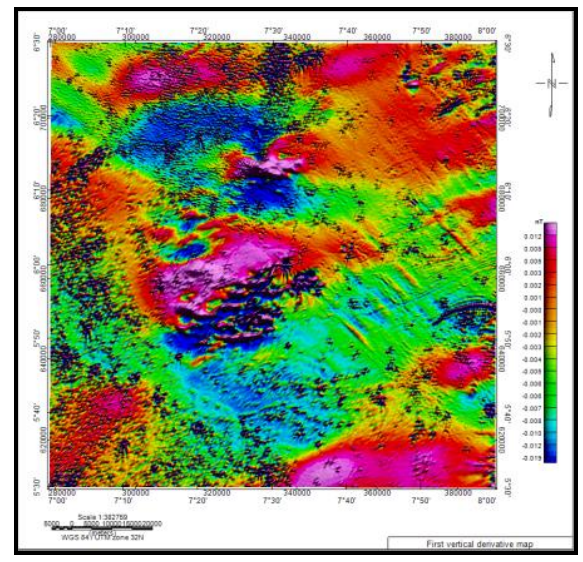

Figure 5. First vertical derivative map of the study area.

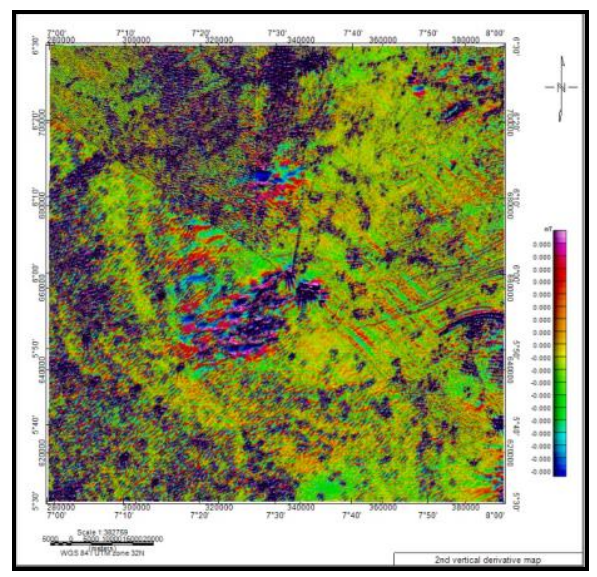

Figure 6. Second Vertical Derivative Map of the Study Area. 


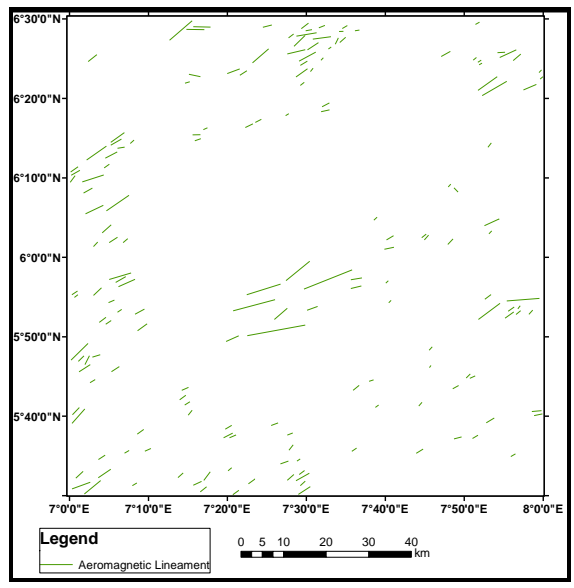

Figure 7. The Digitized Structures from the First Vertical Derivatives Map.

\subsection{Acknowledgement}

The authors are very grateful to Nigerian Geological Survey Agency (NGSA) for supply of data.

\subsection{References}

[1] P. Kearey, M. Brooks, I. Hill, “An introduction to geophysical Exploration, third ed.”, Blackwell Science Ltd., MA, USA, 2002.

[2] B.S.R. Murthy, "Airborne Geophysics and the Indian Scenario”, J. Ind. Geophys. Union, 11 (1), Pp. 1-28, 2007.

[3] L. Quijano, L. Gaspar, M. López-Vicente, M.A.E. Chaparro, J. Machín, and A. Navas, "Soil magnetic susceptibility and Surface topographic characteristics in cultivated Soils", Geography, Pp. 1-6, 2011.

[4] J.M. Reynolds, “An introduction to Applied and Environmental Geophysics”, John Wiley \& Ltd. Bans Lane, Chichester, 1997.

[5] C.O. Ofoegbu, and N.L. Mohan, "Interpretation of aeromagnetic anomalies over part of south-eastern Nigeria using Three-Dimensional Hilbert Transformation”, Pure and Applied Geophysics, Vol. 134, No. 1, Pp. 13-29, 1990.

[6] L.N. Onuba, G.K. Anudu, O.I. Chiaghanam, E.K. Anakuba, "Evaluation of aeromagnetic anomalies over Okigwe area, South-eastern Nigeria", Research Journal of Environmental and Earth Sciences, Vol. 3, No. 5, Pp. 498-507, 2011.

[7] R.A. Onyewuchi, A.I. Opara, C.A Ahiarakwem, F.U. Oko, "Geological interpretations inferred from airborne magnetic and landsat data: case study of Nkalagu area, south-eastern Nigeria”, International Journal of Science and Technology, Vol. 2, No. 4, Pp. 178-191, 2012.

[8] D.I. Igwesi, M.N. Umego, "Interpretation of aeromagnetic anomalies over some part of Lower Benue trough using spectral analysis", International Journal of Scientific \& Technology Research, Vol. 2, No. 8, Pp. 153-165, 2013.

[9] R. Bello, C.C. Ofoha, N. Wehiuzo, "Re-evaluation of sedimentary thickness and Curie point depth of part of lower Benue Trough and Anambra Basin, Nigeria, using regional magnetic field data", Geoscience, Vol. 7, No. 3, Pp. 95-107, 2017.

[10] M.O. Eze, L.I. Mamah, A.J.C. Madu, O. Leonard, “Anambra Basin and Southern Benue Trough using airborne geophysical data”, International Journal of Research in Engineering and Applied Sciences, Vol. 7, No. 5, Pp. 70-80, 2017.

[11] S.B. Ojo, F. Edino, B.D. Ako, K.M. Onuoha, N. Osayande, “Aeromagnetic imaging and characterization of the Anambra Basin, Nigeria, for magnetic hydrocarbon indicators", Ife Journal of Science, Vol. 14, No. 2, Pp. 207-220, 2012.

[12] A.I. Opara, S.O. Onyekuru, A.G. Essien, R.A. Onyewuchi, A.C. Okonkwo, T.T. Emberga, O.P. Nosiri, "Lineament and Tectonic Interpretation Over Abakiliki Area: Evidences from Airborne Magnetic and Landsat ETM Data", International Journal of Research and Innovations in Earth Science, Vol. 2, No. 4, Pp. 2394-1375, 2015.

[13] P. Merki, In: T.J.F. Dessauvigie, A.J. Whiteman (eds.), "Structural Geology of the Cenozoic Niger Delta African Geology", University of Ibadan Press, Ibadan, Pp. 251-268, 1979.

[14] A. Whiteman, “Nigeria: Its Petroleum Geology”, Resources and Potential GrahamandTrotman, London, 1982.

[15] D.R. Adeleye, “Nigerian Late Cretaceous Stratigraphy and paleogeography”, American Association Petroleum Geologists Bulletin 59, Pp. 2302-2313, 1975.

[16] O.K. Agagu, E.A. Fayose, S.W. Peters, "Stratigraphy and Sedimentation in the Santonian, Anambra of Eastern Nigeria", Nigerian Journal of Mining and Geology, Vol. 22, Pp. 25-63, 1985

[17] R.C. Murat, In: T.J.F. Dessauvigie, A.J. Whiteman (eds.), "Stratigraphy and paleogeography of the Cretaceous and Lower Tertiary in Southern Nigeria", University of Ibadan Press, Ibadan, Pp. 635-648, 1972.

[18] NGSA, 1:100,000 high resolution aeromagnetic sheets 301 (udi), 302 (Nkalagu), 312 (Okigwe) and 313 (Afikpo) lies between latitude 5:30-6:30 and longitude 7:0-8:0, Abuja, Nigeria, 2005. 